\title{
A review of regeneration and genetic transformation in cowpea (Vigna unguiculata L. Walp)
}

\author{
Tie Manman, Luo Qian, Tan Huaqiang, Zhu Yongpeng, Lai Jia and Li Huanxiu* \\ College of Horticulture, Sichuan Agricultural University, Ya'an 625014, Sichuan, China.
}

Accepted 26 March, 2013

\begin{abstract}
Biotechnology techniques including plant tissue culture and recombinant DNA technologies are important tools that can complement traditional breeding. Progress has been slow in cowpea (Vigna unguiculata L.), mainly due to its recalcitrant in plant regeneration and genetic transformation. Despite this, some achievements have been obtained. This review presents a consolidated account of explants used, mode of regeneration and genetic transformation in cowpea. Furthermore, it describes the discussion of some existing problems about regeneration and genetic transformation in cowpea. The authors find that organogenesis pathway and Agrobacterium mediated method is widely used in this area in cowpea recent years. Other explants such as anther should be researched in regeneration in cowpea and the affecting factors during transformation process should be explored further.
\end{abstract}

Key words: Regeneration, organogenesis, somatic embryogenesis, genetic transformation, cowpea.

\section{INTRODUCTION}

Cowpea (Vigna unguiculata L.), widely grown in Africa, Latin America, Southeast Asia and southwestern regions of North America (FAOSTAT, 2006), is a major source of high-quality dietary protein and energy for local people. It plays a critical role in the lives of millions of people in developing countries of Africa and Asia. In spite of the great importance of this crop, its productivity is low, which is mainly limited by the damage caused by biotic constraints like virus, bacteria, fungus, insects, plants, and nematodes, as well as abiotic stresses such as heat and drought (Singh et al., 1997). In addition, limited genetic diversity in cowpea breeding programs is of special concern because cowpea appears to have lower inherent genetic diversity than other cultivated crops as a result of a hypothesized single domestication event (Fang et al., 2007). Consequently, the transfer of exogenous gene by genetic engineering could potentially accelerate the breeding process. Although some resistance genes to insect pests and fungi have been bred in some
International Institute of Tropical Agriculture (IITA) cowpea varieties (Latunde-Dada, 1990), the attempts using conventional breeding methods to introduce the resistance genes into the cultivated cowpea have made little progress for the strong hybrid-incompatibility. Hence, genetic engineering approaches stand out as the most effective alternative strategy to overcome the production constraints (Zaidi et al., 2005). This paper reviews previous work on cowpea tissue culture and transformation.

\section{REGENERATION SYSTEM}

There are two pathways in plant regeneration, namely organogenesis and embryogenesis, both of which have been used in cowpea regeneration. Some of the reports affected by many factors, such as appropriate genotype, optimal explants, certain culture medium, specific plant 
growth regulators, etc.

\section{Organogenesis pathway}

Organogenesis pathway means that the regenerative plants differentiate shoot buds directly through eristematic center, thus forming a complete plant eventually. It could be divided into direct organogenesis and indirect organo genesis based on the presence or absence of callus. The successful establishment of a regeneration system is affected by many factors, such as appropriate genotype, optimal explants, certain culture medium, specific plant growth regulators, etc.

\section{Effect of genotype}

Genotype is one of the main factors that influence the regeneration in different plant species. Among the different factors affecting cowpea regeneration, the organogenic response varies widely on account of the genotypes. The cotyledons of 36 genotypes of cowpea were cultured by Brar et al. (1999a), 19 among which failed to induce buds. Regeneration percentages ( 1 to $11 \%$ ) and the numbers of shoots (4 to 12 per explant) of the other 17 cowpea genotypes showed significant differences. Chaudhury et al. (2007) tested the regeneration capability of seven cultivars of $V$. unguiculata that is, IC-202786, IC-257438, IC-259159, IC-243501, V-240, V-130 and V-585. The frequency of regeneration and number of multiple shoots from the explants were affected by the genotype. Of these, the commercially grown cultivar V-585 produced the highest number of shoots, with an average of 6.8 shoots per explant and an average length of $1.7 \mathrm{~cm}$. Other scholars like Pellegrineschi (1997); Popelk et al. (2006); Manoharan et al. (2008); Solleti et al. (2008a); Raveendar et al. (2009); Bakshi et al. (2012a) also concluded that genotypes have influence on shoot regeneration.

\section{Type and size of explants}

The plant regeneration is largely governed by the appropriate choice of the explants. For legume, there are many kinds of explants to choose. Epicotyls, hypocotyls, cotyledons, cotyledonary nodes, shoot tips, plumular apices and shoot meristems (Table 1) are commonly used in regeneration via organogenesis pathway. Both explants types and the size of explants have great influence on regeneration.

Amitha and Reddy (1996) studied the regeneration potential of epicotyl, cotyledon and hypocotyl explants of cowpea. The shoot buds produced from different explants proliferated and regenerated into complete plants. Bao et al. (2006) take 5 parts of cowpea that is, hypocotyls, epicotyls, stem segments, leaves and terminal buds under the same condition for callus and buds induction. All the 5 types of explant are able to induce callus in spite of the obviously different induction rate. On the optimal medium selected for different explants, the callus induced from hypocotyls, epicotyls, stem segments and terminal buds are easy to differentiate adventitious buds, but the leaves cannot produce buds. Li (2011) did a similar test, taking leaves, stem segments, cotyledons and cotyledonary nodes as explants, founding that leaves and stem segments could only induce callus and could not differentiate buds, while the cotyledon and cotyledonary node explants could induce shoots directly, and the shoot induction rate of cotyledonary nodes could reach $100 \%$. Diallo et al. (2008) used three types of explants, that is, cotyledonary nodes with one cotyledon, two cotyledons and without cotyledon. The shoots multiplication rate was influenced by the number of cotyledons. Explants with both entire cotyledons produced the greater number of shoots on the optimal medium, followed by the explants with one cotyledon. The worst results were observed with explants without cotyledons. This is consistent with the research of Chaudhury et al. (2007) and Raveendar et al. (2009). However, researchers such as Chaudhury et al. (2007); Solleti et al. (2008b), Bakshi et al. (2011, 2012a) used cotyledonary nodes without cotyledons for transformation, they thought it will facilitate the transformation of genes and the cleaning of fungus liquid. Cowpea cotyledonary node is widely used in cowpea regeneration recent years due to its efficient transformation regeneration frequency.

In addition to explant types, the cutting mode and size of explants have significant effects on regeneration. Three types of explants were used for cowpea regeneration by Le et al. (2002), that is, longitudinal thin cell layers $(0.5 \times 10 \mathrm{~mm})$, transverse thin cell layers $(0.3$ to $0.5 \mathrm{~mm})$ and longitudinal half axis $(5 \times 10 \mathrm{~mm})$. The buds induction frequency of both longitudinal thin cell layers and longitudinal half axis could reach $100 \%, 32.5$ and 23.2 buds were harvested per explants respectively. While the frequency of the transverse thin cell layers was only $52.9 \%$, and the average buds was 11.7 per explant. Muthukumar et al. (1996) studied the regenerative capacity of different cutting methods on cotyledons. Whole cotyledons with intact proximal end without cotyledonary node tissue regenerated well. Regeneration rate of the proximal end of longitudinally sliced halves was higher than the transverse halves containing proximal end.

\section{Effect of basal medium and plant growth regulators}

The medium is the basis of tissue culture. Medium containing different ingredients will produce different results in the cultivation of cowpea explants. Three kind of basal medium that is, MS, B5 and MSB (MS salts + B5 vitamins) were commonly used in cowpea tissue culture. 
Table 1. In vitro plant regeneration in cowpea.

\begin{tabular}{|c|c|c|c|}
\hline Explants type & Mode of regeneration & Medium+PGRs & References \\
\hline Shoot apical meristems & Organogenesis & $\mathrm{MS}+\mathrm{BA}+\mathrm{NAA}$ & Kartha et al. (1981) \\
\hline Immature cotyledons & Somatic embryogenesis & $\begin{array}{l}\mathrm{MSB}+2,4-\mathrm{D}+\mathrm{BA} \\
\mathrm{MSB}+\mathrm{IAA}+\mathrm{KT}\end{array}$ & Li et al. (1993) \\
\hline Primary leaves & Organogenesis & $\mathrm{B} 5+\mathrm{BA}$ & Muthukumar et al. (1995) \\
\hline Cotyledons & Organogenesis & $\mathrm{B} 5+\mathrm{BA}$ & Muthukumar et al. (1996) \\
\hline $\begin{array}{l}\text { Epicotyls, cotyledons and } \\
\text { hypocotyls }\end{array}$ & Organogenesis & $M S+B A / I A A$ & Amitha and Reddy (1996) \\
\hline Shoot tip & Organogenesis & $\mathrm{MS}+\mathrm{BA}+\mathrm{NAA} / 2,4-\mathrm{D}$ & Brar et al. (1997) \\
\hline Hypocotyls and cotyledons & Organogenesis & $\mathrm{BM} / \mathrm{FBM}+\mathrm{BA} / \mathrm{ZE} / \mathrm{KT}+\mathrm{IAA} / \mathrm{NAA}$ & Pellegrineschi (1997) \\
\hline Cotyledons & Organogenesis & $\mathrm{MS}+\mathrm{BA}$ & Brar et al. (1999a) \\
\hline Primary leaves & Somatic embryogenesis & $\mathrm{MS}+2,4-\mathrm{D} / \mathrm{ABA}$ & Anand et al. (2000) \\
\hline $\begin{array}{l}\text { cotyledonary node thin cell layer } \\
\text { explants }\end{array}$ & Organogenesis & MSB+IBA/TDZ & Le et al. (2002) \\
\hline Primary leaves & Somatic embryogenesis & MSB/ B5+2,4-D/ABA & Ramakrishnan et al. (2005) \\
\hline Embryo axes & Organogenesis & MS+NAA/BA & Odutayo et al. 2005) \\
\hline Shoot apices & Organogenesis & $\mathrm{MSB}+\mathrm{BA} / \mathrm{GA} 3 / \mathrm{IBA}$ & Mao et al. (2006) \\
\hline $\begin{array}{l}\text { Hypocotyls, epicotyls, stem } \\
\text { segments, leaves and terminal } \\
\text { buds }\end{array}$ & Organogenesis & $\mathrm{MS}+\mathrm{BA} / \mathrm{NAA} / 2,4-\mathrm{D}$ & Bao et al. (2006) \\
\hline Cotyledonary nodes & Organogenesis & MSB/MS+BA/IBA & Chaudhury et al. (2007) \\
\hline Embryonic axis explants & Organogenesis & $\mathrm{MSB}+\mathrm{BA} / \mathrm{ZT} / \mathrm{GA} 3 / \mathrm{IAA}$ & Raji et al. 2008) \\
\hline Cotyledonary nodes & Organogenesis & MS/ B5+BA/KT/NAA & Diallo et al. (2008) \\
\hline Shoot meristems & Organogenesis & $\mathrm{MS}+\mathrm{BA}$ & Manoharan et al. (2008) \\
\hline Embryonic axis explants & Organogenesis & $\mathrm{MSB}+\mathrm{BA}$ & Yusuf et al. (2008) \\
\hline Cotyledonary nodes & Organogenesis & $\mathrm{MSB}+\mathrm{BA}$ & Raveendar et al. 92009) \\
\hline Cotyledonary nodes & Organogenesis & MSB/MS+ BA/KT/GA3/IBA & Solleti et al. (2008b) \\
\hline Shoot meristems & Organogenesis & $\mathrm{MS}+\mathrm{BA} / \mathrm{NAA} / \mathrm{BA}$ & Aasim et al. (2008) \\
\hline Shoot tip explants & Organogenesis & $\mathrm{MS}+\mathrm{TDZ} / \mathrm{IBA}$ & Aasim et al. (2009a) \\
\hline Plumular apices & Organogenesis & $\mathrm{MS}+\mathrm{BA} / \mathrm{NAA} / \mathrm{BA}$ & Aasim et al. (2009b) \\
\hline $\begin{array}{l}\text { Leaves, stem segments, } \\
\text { cotyledons, cotyledonary nodes }\end{array}$ & Organogenesis & MSB+BA/TDZ+IBA & Li 2011) \\
\hline Cotyledonary nodes & Organogenesis & MSB+BA/TDZ & Bakshi et al. $(2011,2012 a)$ \\
\hline
\end{tabular}

Chaudhury et al. (2007) used MSB as the basal medium for bud induction while MS for rooting. Diallo et al. (2008) studied the influence of basal medium for cowpea regeneration. More efficient multiple shoots from cotyledonary node explants were obtained on B5 medium. But MS medium was more conducive to shoot elongation. Rooting was favored on half strength MS medium (Bao et al., 2006).

Plant hormones play an important role in the process of cowpea regeneration. The type and concentration of hormone vary at different stages of induction.

In general, higher concentration of cytokinin alone or in combination with a lower concentration of auxin was often used for shoot buds induction. For example, Chaudhury et al. (2007) assessed the effect of different concentration (2.5-10 $\mu \mathrm{M})$ of BA on shoot buds induction. They observed that BA at $5 \mu \mathrm{M}(1.25 \mathrm{mg} / \mathrm{L})$ was optimal for shoot regeneration as it induced an average of 6.3 shoots (three-fold increase than control) in $80 \%$ of the cultures.
Muthukumar et al. (1995) and Solleti et al. (2008a) came to the same conclusion. Basal medium supplemented with $4.4 \mu \mathrm{M}(1 \mathrm{mg} / \mathrm{L}) \mathrm{BA}$ was used for shoot formation by other scholars (Diallo et al., 2008; Aasim et al., 2009b) from different types of explants (Table 1). Muthukumar et al. (1996) found that when the concentration of BA exceeds $15 \mu \mathrm{M}(3.5 \mathrm{mg} / \mathrm{L})$, the ability of shoot regeneration was inhibited clearly. The regenerated buds were difficult to elongate with the increasing of BA concentration.

Aasim et al. (2009a) compared the effects of different concentrations of TDZ $(0.15$ to $0.35 \mathrm{mg} / \mathrm{L})$ on shoot regeneration from shoot tip explants. The results presented that shoot regeneration rate raised with increase in TDZ concentration. But higher TDZ concentratlon was observed inhibiting shoot elongation. BA was better than TDZ on shoot regeneration which was reported by Solleti et al. (2008a). High concentration of cytokinins (BA and KT) in conjunction with low concentration 
of auxins (NAA and 2,4-D) produced higher number of shoots together with higher elongation. Aasim et al. (2009b) and $\mathrm{Li}$ (2011) investigated and found that adding low concentration of auxins or not had no clear effect on shoot induction. Many studies showed that $\mathrm{KT}$ and $\mathrm{GA}_{3}$ have apparently stimulative effect on the elongation of adventitious shoots. Solleti et al. (2008a) assessed the effect of $\mathrm{KT}$ and $\mathrm{GA}_{3}$ on shoot elongation. The results showed that $0.5 \mu \mathrm{M} \mathrm{KT}$ enhanced the shoot elongation. Medium containing $\mathrm{GA}_{3}$ induced non-uniform elongation and the elongated shoots were found thin and lanky, unsuitable for rooting.

Some types of auxin were used for rooting such as IBA (Chaudhury et al., 2007; Diallo et al., 2008; Solleti et al., 2008; Aasim et al., 2009a; Li, 2011), IAA (Mao et al., 2006; Raji et al., 2008) and NAA (Brar et al., 1997;

Diallo et al., 2008) and 2,4-D (Brar et al., 1997). Diallo et al. (2008) explored the influence of different concentration $(0.5-5 \mathrm{mg} / \mathrm{L})$ of IBA in comparison with NAA. IBA was found to be more effective for rooting because of the higher root length and activity. Media containing $2.5 \mu \mathrm{M}(0.5 \mathrm{mg} / \mathrm{L})$ IBA were used for rooting (Aasim et al., 2009a; Chaudhury et al., 2007; Solleti et al., 2008a; Li, 2011). Rooting formation disposed with NAA or 2,4-D was described by Brar et al. (1997). NAA was better for rhizogenesis at the concentration of 0.1-0.5 $\mathrm{mg} / \mathrm{L}$. Some scholars, however, believed that there was no apparent promoting on rhizogenesis when adding auxins (Mao et al., 2006). Raji et al. (2008) also confirmed that the root induction rate on medium without hormone could reach $100 \%$, same as the effect of low concentration $(0.01 \mathrm{mg} / \mathrm{L})$ of IAA. Furthermore, increasing the concentration of IAA would inhibit root formation.

Many studies have found that adding cytokinin to seedling medium have a great impact on regeneration. Amitha and Reddy (1996) preconditioned the seedlings with BA (2 mg/L) and CM (coconut milk) (5\%) on MS medium. The regeneration frequency and the shoot buds number presented variety compared to the control group. Brar et al. (1999a) came to a conclusion that explants derived from the seedlings growing on the medium supplemented with $66.6 \mu \mathrm{M}(15 \mathrm{mg} / \mathrm{L}) \mathrm{BA}$ resulted in the highest regeneration percentage. While the highest number of shoots was observed from those with 155.3 $\mu \mathrm{M}$ (35 mg/L) BA. Le et al. (2002) preprocessed the seedlings with different concentrations of $\operatorname{TDZ}(0,1,5$, $10,20$ and $50 \mu \mathrm{M})$. The result indicated that the addition of $10 \mu \mathrm{M} / \mathrm{L}$ TDZ was the best for buds induction. Similar result had been reported by Bakshi et al. (2012a). A 10 $\mu \mathrm{M}$ TDZ preconditioning enhanced shoot proliferation ability. Aasim et al. (2009b) observed that seeds precultured with $10 \mathrm{mg} / \mathrm{L}$ BA for 5 days could increase the regeneration rate of plumular apices. While Raveendar et al. (2009) drew a conclusion that seeds germinated on MSB medium containing $13.3 \mu \mathrm{M}(4 \mathrm{mg} / \mathrm{L}) \mathrm{BA}$ for 3 days and cultured on the subsequent optimal medium produced the highest number of shoots $(7.2 \pm 0.8$ per explant), evidently higher than that of control $(4.7 \pm 0.6$ per explant).

\section{Effect of other additives}

As a kind of growth regulator, ethylene has an effect on in vitro culture. Brar et al. (1999b) studied the regeneration of cowpea from cotyledons with the processing of three ethylene inhibitors respectively, that is, silver nitrate $\left(\mathrm{AgNO}_{3}\right), 2,5$-norbornadiene and cobalt chloride $\left(\mathrm{CoCl}_{2}\right)$. They found the regeneration varied owing to the concentration and type of ethylene inhibitors. The addition of $50 \mu \mathrm{M} \mathrm{AgNO}_{3}$ or $100 \mu \mathrm{M}$ 2,5-norbornadiene could improve induction rate of adventitious buds. The greatest percentage of regeneration was observed by

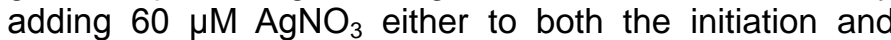
regeneration stages, or to only the regeneration stage. $\mathrm{CoCl}_{2}$ at $25 \mu \mathrm{M}$ or 2,5-norbornadiene at $100 \mu \mathrm{M}$ enhanced the number of shoots per explant. Either $25 \mu \mathrm{M}$ $\mathrm{CoCl}_{2}$ or 2,5-norbornadiene was the best for shoot elongation. Mao et al. (2006) found that the addition of $58.8 \mu \mathrm{M} \mathrm{AgNO}_{3}$ was helpful to reduce callus browning, and this supported the conclusion of Brar et al. (1999b). Aasim et al. (2009b) added $3 \mathrm{~g} / \mathrm{L}$ active charcoal and $1.25 \mathrm{mg} / \mathrm{L}$ polyvinylpyrrolidone (PVP) in the medium. High frequency of callus induction could be obtained due to significantly inhibition of the bleeding of phenolic compounds from the explants.

\section{Somatic embryogenesis}

Embryogenesis means that the individual cells experience a series of morphological development stages similar to the formation of zygotic embryo. Embryogenesis is considered better than other in vitro propagation systems as its relatively high genetic uniformity and shorter time in regeneration and propagation. Somatic embryogenesis takes a prominent role in clonal propagation when integrated with a conventional breeding program and molecular and cellular biotechnology. It provides a valuable tool to enhance the pace of genetic improvement of commercial crop species (Stasolla and Yeung, 2003).

\section{Type of explants and plant growth regulators}

Explants have been used in cowpea somatic embryogenesis pathway were only immature embryo ( $\mathrm{Li}$ et al., 1993) and primary leaves (Anand et al., 2000; Ramakrishnan et al., 2005). Li et al. (1993) studied the cowpea somatic embryogenesis using immature embryo which developed 10 to 15 days after flowering. The results showed that at the callus induction stage by protoplast, the improved MS medium was more effective than B5 medium. 
The former frequency of cell division at the tenth day was $27.7 \%$, while the latter was $20.5 \%$. In their study, MSB was employed as the basal medium in the subsequent culture. 2,4-D and BA was added in callus subculture, while IAA and KT was added in the developmental stages of proembryo. Anand et al. (2000) took leaf segments from young seedlings as explants, used MS as basal medium and added 2,4-D as phytohormone. Maximum proliferation of callus was observed within 15 days on medium containing $6.78 \mu \mathrm{M}$ 2,4-D. $2.26 \mu \mathrm{M}$ 2,4-D was the best for embryos development. This conclusion was confirmed by Ramakrishnan et al. (2005). In the process of torpedostage somatic embryo transfer to cotyledonary stage, the concentration of 2,4-D shoud be reduced. The presence of ABA was also crucial for the maturity of embryo (Anand et al., 2000; Ramakrishnan et al., 2005). The optimum concentration of ABA is $5 \mu \mathrm{M}$. Ramakrishnan et al. (2005) compared the different effects of TDZ and ZE in plantlet conversion. The results indicated that TDZ was crucial for plantlet conversion, while ZE would cause recallusing of cotyledonary-stage embryos. Extension of hypocotyls and complete development of plantlet was achieved on halfstrength B5 medium supplemented with $3 \%$ maltose, $2500 \mathrm{mg} / \mathrm{L}$ potassium nitrate and $0.05 \mathrm{mg} / \mathrm{L}$ thidiazuron (TDZ) with $32 \%$ regeneration frequency. Nevertheless, Anand et al. (2000) thought that ZE had an enormous effect on plantlet conversion. The maximum percentage of conversion (21.8\%) occurred on $1 / 2 \mathrm{MS}$ semisolid medium containing ZE $(2 \mu \mathrm{M}), \mathrm{ABA}(5 \mu \mathrm{M})$ and mannitol (3\%).

\section{Type of the basal medium and other additives}

According to Ramakrishnan et al. (2005), MSB had a better effect on embryogenic callus induction and proembryo formation. B5 was essential to the maturity of embryos and the reduction of the number of abnormal embryoid, and 1/2 B5 was very important for cotyledonary-stage somatic embryos to convert into complete plantlets. MS medium was ordinary in the whole process of cowpea somatic embryogenesis without any particular superior effect. They also found that adding 150 $\mathrm{mg} / \mathrm{l} \mathrm{CH}$ and $100 \mathrm{mg} / \mathrm{l} \mathrm{Gln}$ to medium which contain $1.5 \mathrm{mg} / \mathrm{l}$ 2,4-D would promote embryogenic callus induction. Among different forms of carbon source, 3\% sucrose was better than $3 \%$ glucose and maltose in embryogenic callus induction. The frequency of callus induction could reach $100 \%$ with $3 \%$ sucrose and MSB medium containing $150 \mathrm{mg} / \mathrm{L} \mathrm{CH}$ and $100 \mathrm{mg} / \mathrm{L}$ Gln. However, sugar alcohols such as mannitol and sorbitol were not effective in increasing the frequency of callus induction irrespective of the media.

\section{Other factors}

Anand et al. (2000) drew the conclusion that at the stage of suspension-cultured cells of cowpea, a shaking speed of $90 \mathrm{rpm}$ and $0.4 \mathrm{ml}$ packed cell volume per $25 \mathrm{ml}$ medium were found to be optimal for maintaining suspension cultures.

\section{ESTABLISHMENT OF COWPEA GENETIC TRANSFORMATION SYSTEM}

There are a variety of methods to establish plant genetic transformation system, but only Agrobacterium mediated and particle bombardment transformation methods have been used in cowpea to date.

\section{Agrobacterium mediated genetic transformation}

Garcia et al. $(1986,1987)$ were the first to employ transformation experiments in cowpea (Table 2). They used an Agrobacterium-mediated system to transform cowpea leaf disc explants. Although kanamycin-resistant callus was obtained, the transgenic calli failed to regenerate into mature plants. Perkins et al. (1987) and Filippone (1990) achieved transgenic calli from different explants co-cultivated with Agrobacterium tumefaciens respectively, but no intact transgenic plants could be regenerated either. Penza et al. (1991) reported they obtained chimeric transgenic cowpea plants from longitudinal mature embryo slices co-cultivated with $A$. tumefaciens.

The report showed that transformed cells mainly located in the subepidermal regions of the plant stems and there was no evidence of stable integration of the introduced genes. All the experiments above demonstrated cowpea is susceptible to $A$. tumefaciens, however, failed to regenerate transgenic plants.

The first production of transgenic cowpea plants was reported by Muthukumar et al. (1996). They used deembryonated cotyledons as explants co-cultivating with A. tumefaciens, followed by transfer of the explants to a selective medium, and recovered hygromycin-resistant shoots that grew to maturity and set seed. Only one of the plants was confirmed to be transgenic, but the seeds showed failure to germinate and no evidence of transgene transmission to the progeny was obtained. Similarly, Kononowicz et al. (1997) developed an efficient genetic transformation system for cowpea. The introduced gene was detected in TO cowpea plants but the evidence of transferred gene in the T1 progeny was not presented.

The first success of obtaining transgenic cowpea and transmitting the transgene to their progenies following Mendelian laws was described by Popelka et al. (2006).They obtained transgenic plants with a frequency of transformation of 0.05 to $0.15 \%$ which is slightly lower. This technique was improved by Chaudhury et al. (2007) who used cotyledonary node explants as Popelka's group, but they inflicted wounds at the nodal region with 
Table 2. Key dates of cowpea genetic transformation.

\begin{tabular}{|c|c|c|c|c|}
\hline Date & Methods & Gene & Result & References \\
\hline 1986 & Agbacterium tumefaciens & Kanamycin resistant & Transgenic calli & Garcia et al. (1986) \\
\hline 1987 & Agbacterium tumefaciens & Kanamycin resistant & Transgenic calli & Garcia et al. (1987) \\
\hline 1987 & Agbacterium tumefaciens & Kanamycin resistant & Transgenic calli & Perkins et al. (1987) \\
\hline 1991 & Agrobacterium tumefaciens & gus & Putative transgenic plant & Penza et al. (1991) \\
\hline 1992 & Biolistic & gus & Transient expression & Penza et al. (1992) \\
\hline 1993 & Biolistic & gus & Transient expression & Akella and Lurquin (1993) \\
\hline 1996 & Agrobacterium tumefaciens & Hygromycin resistant & $\begin{array}{l}\text { Transgenic plants, no } \\
\text { evidence of transgenic } \\
\text { progenies }\end{array}$ & Muthukumar et al. (1996) \\
\hline 1997 & $\begin{array}{l}\text { Agrobacterium tumefaciens } \\
\text { /Biolistic }\end{array}$ & a-amylase inhibitor & $\begin{array}{l}\text { Transgenic plants, no } \\
\text { evidence of transgenic } \\
\text { progenies }\end{array}$ & Kononowicz et al. (1997) \\
\hline 2003 & Biolistic & bar & $\begin{array}{l}\text { Small proportion of } \\
\text { transgenic progenies }\end{array}$ & Ikea et al. (2003) \\
\hline 2006 & Agrobacterium tumefaciens & bar & Transgenic progenies & Popelka et al. (2006) \\
\hline 2007 & Agrobacterium tumefaciens & Kanamycin resistant & Transgenic progenies & Chaudhury et al. (2007) \\
\hline 2008 & Agrobacterium tumefaciens & gus & Transgenic shoots & Raji et al.,2008 \\
\hline 2008 & Biolistic & ahas & Transgenic progenies & Ivo et al. (2008) \\
\hline 2008 & Agrobacterium tumefaciens & nptll and gus & Transgenic progenies & Solleti et al. (2008a) \\
\hline 2008 & Agrobacterium tumefaciens & $\alpha$-amylase inhibitor-1 & Transgenic progenies & Solleti et al. (2008b) \\
\hline 2011 & Agrobacterium tumefaciens & cry $1 \mathrm{Ac}$ & Transgenic plants & Bakshi et al. (2011) \\
\hline 2012 & Agrobacterium tumefaciens & nptll and gus & Transgenic progenies & Bakshi et al. (2012a) \\
\hline 2012 & Agrobacterium tumefaciens & pmi & Transgenic progenies & Bakshi et al. (2012b) \\
\hline
\end{tabular}

sterile needle prior to Agrobacterium infection and generated transgenic plants with an efficiency of $0.76 \%$.

Solleti's group reported much higher transformation efficiencies of 1.64 and $1.67 \%$. They added virulence genes in resident pSB1 vector in Agrobacterium strain LBA4404 and used a regimen of geneticin selection at 45 $\mathrm{mg} / \mathrm{L}$, thereby increasing the transformation efficiency and providing a rapid and efficient identification system (Solleti et al. 2008a).

Using the same regimen, they introduced the bean aamylase inhibitor-1 (aAl-1) gene into an Indian cowpea cultivar, and obtained the transgenic seeds that strongly inhibited the development of $C$. maculatus and $C$. chinensis (Solleti et al., 2008b). Bakshi et al. (2011) improved the method of Agrobacterium-mediated transformation of cowpea. They used both sonication and vacuum infiltration to dispose cotyledonary node explants with $A$. tumefaciens. The stable transformation efficiency of treatments increased by $88.4 \%$ compared to the traditional Agrobacterium-mediated transformation in cowpea. Shortly after that, they described how seedling preconditioning in thidiazuron (TDZ) and BA affected the shoot proliferation potential of cotyledonary nodes and transformation process. Explants of TDZ preconditioned seedlings presented significantly higher transient transformation rate as compared to that of explants of BA preconditioned seedlings. Best results were obtained under the condition of explants deriving from seedling preconditioning in $10 \mu \mathrm{M}$ TDZ for 4 days. The transformation rate enhanced from 0.6 to $2.1 \%$ on comparison of in absence and presence of seedling preconditioning (Bakshi et al., 2012a). Besides, they developed a new method for obtaining transgenic cowpea using of pmi selection. This system was based on the ability to inhibit shoot organogenesis from nontransformed explants cultured on medium containing mannose as a carbon source, thus obtaining efficient shoot proliferation (Bakshi et al., 2012b).

\section{Genetic transformation by particle bombardment}

Penza's and Akella's groups separately applied electroporation method via intact cowpea embryonic tissues, using naked DNA in the presence of protectants such as spermine (Penza et al., 1992; Akella and Lurquin, 1993), but no stably transformed plants were obtained. Ikea et al. (2003) were able to generate transgenic cowpea plants using the particle bombardment process. However, the transgenes were transmitted to only a small proportion of the progeny and there was no further molecular evidence of stable transformation with Mendelian laws. Ivo et al. (2008), employing the biolistic method of gene transfer, were able to generate stable transgenic cowpea plants from bombarded embryonic axes. 
Their system is built on combining the use of the herbicide imazapyr to select transformed meristematic cells and a simple tissue culture protocol. The gus gene was used as a reporter gene and their transformation frequency was $0.90 \%$, thereby presenting the first work on the use of this approach of biolistic-mediated for generating transgenic cowpea plants and obtaining the progenies (first and second generations) that cosegregated in a Mendelian fashion.

\section{CONCLUSIONS AND FUTURE PROSPECTS}

Significant progress aimed towards regeneration and genetic transformation of cowpea has been made, but still there is a long way to go in this direction. As has been described above, cowpea regeneration depended mainly on direct or indirect organogenesis pathway. Recent years, the most desirable mode of regeneration is via direct organogenesis, and cotyledonary node explants have been preferred. In addition, some researchers have attempted to establish regeneration system via somatic embryogenesis. It is important to note that a liquid suspension protocol is relatively efficient, because a high frequency of somatic embryos can be obtained, and individual embryos can be handled easily for further biotechnological applications (Anand et al., 2000).

In general, two methods including Agrobacteriummediated and particle bombardment have been successfully applied to genetic transformation of cowpea. The continued search has lead to the obtaining of transgenic cowpea and their progenies. Although the transformation frequency keeps increasing, it is still lower compared to other legumes. Furthermore, the efficient recovery of transformed plants depends not only on the mode of regeneration and choice of transformation procedure but also on selectable markers (Chandra and Pental, 2003). Although some results have been obtained with the negative selection protocols, it has not proved an efficient method. The selection of putative transformed shoots on antibiotic or herbicide-supplemented medium lead to regeneration decreasing, growth retardation and low rooting efficiency, all were caused by long-time exposure to stringent selection. Using the 6phosphomannose isomerase gene as the selectable marker (Bakshi et al., 2011) has been the one and only new attempt for obtaining recovery transgenic cowpea, and further research is needed. In conclusion, developing protocols to enhance regeneration still remains an important goal in cowpea, and the recovery of transgenic cowpea should be the focus of future research.

Abbreviations: ABA, Abscisic acid;
benzylaminopurine; BM, basal medium; CH, casein
hydrolysate; FBM, fortified basal medium; GA3,
gibberellin; GLN, L-glutamic acid-5-amide; IAA,
indoleacetic acid; IBA, indole-3-butytric acid; IITA,

international institute of tropical agriculture; KT, N6furfuryladenine; MS, Murashige and Skoog (1962) medium; MSB, Murashige and Skoog (1962) salts and gamborg b5 vitamins (1968) medium; NAA, Anaphthlcetic acid; PGRS, plant growth regulators; PVP, polyvinylpyrrolidone; TCL, thin cell layer; TDZ, THIDIAZURON; 2,4-D, (2,4- dichlorphenoxy) acetic acid; ZE, zeatin.

\section{REFERENCES}

Aasim M, Khawar KM, Ozcan S (2008). In vitro micropropagation from plumular apices of Turkish cowpea (Vigna unguiculata L.) cultivar Akkiz. Sci. Hortic. 122:468-471.

Aasim M, Khawar KM, Ozcan S (2009a). Comparison of shoot regeneration on different concentrations of thidiazuron from shoot tip explants of cowpea on gelrite and agar containing medium. Notulae Botanicae Horti Agrobo. Cluj-Napoca 37(1):89-93.

Aasim M, Khawar KM, Ozcan S (2009b). In vitro micropropagation from plumular apices of Turkish cowpea (Vigna unguiculata L.) cultivar Akkiz. Sci. Hortic. 122:468-471.

Akella, V, Lurquin PF (1993). Expression in cowpea seedlings of chimeric transgenes after electroporation into seed-derived embryos. Plant Cell Rep. 12:110-117.

Amitha K, Reddy TP (1996). Regeneration of plantlets from different explants and callus cultures of cowpea (Vigna unguiculata L.). Phytomorphology 46(3):207-211.

Anand RP, Ganapathi A, Anbazhagan VR, Vengadesan G, Selvaraj N (2000). High frequency plant regeneration via somatic embryogenesis in cell suspension cultures of cowpea vigna unguiculata (L.) walp. In Vitro Cell. Dev. Biol. Plant. 36:475-480.

Bakshi S, Sadhukhan A, Mishra S, Sahoo L (2011). Improved Agrobacterium-mediated transformation of cowpea via sonication and vacuum infiltration. Plant Cell Rep. 30:2281-2292.

Bakshi S, Roy NK, Sahoo L (2012a). Seedling preconditionng in thidiazuron enhances axillary shoot proliferation and recovery of transgenic cowpea plants. Plant Cell Tiss.110:77-91.

Bakshi S, Saha B, Roy NK, Mishra S, Panda SK, Sahoo L (2012b). Successful recovery of transgenic cowpea (Vigna unguiculata) using the 6-phosphomannose isomerase gene as the selectable marker Plant Cell Rep. 31:1093-1103.

Bao YH, Bai Y, Wang YM, Huang YY, Xu XJ, Xu QW (2006). The regeneration of cowpea (Vigna unguiculata L.). Agric. Sci. GuangDong 4:31-33.

Brar MS, Al-Khayri, JM, Shambein CE, Mcnew RW, Morelock TE, Anderson EJ (1997). In vitro shoot tip multiplication of cowpea Vigna unguiculata (L.) Walp. In Vitro Cell. Dev. Biol. Plant 33:114-118.

Brar MS, Al-Khayri JM, Morelock TE, Anderson EJ (1999a). Genotypic response of cowpea (Vigna unguiculata L.) to in vitro regeneration from cotyledon explants. In Vitro Cell. Dev. Biol. Plant. 35:8-12.

Brar MS, Moore MJ, Al-Khayri JM, Morelock TE, Anderson EJ (1999b). Ethylene inhibitors promote in vitro regeneration of cowpea (Vigna unguiculata L.). In Vitro Cell. Dev. Biol.Plant 35:222-225.

Chandra A, Pental D (2003). Regeneration and genetic transformation of grain legumes: An overview. Curr. Sci. 84:381-387.

Chaudhury D, Madanpotra S, Jaiwal R, Saini R, Kumar AP, Jaiwal PK (2007). Agrobacterium tumefaciens-mediated high frequency genetic transformation of an Indian cowpea (Vigna unguiculata L. Walp.) cultivar and transmission of transgenes into progeny. Plant Sci. 172:692-700.

Diallo MS, Ndiaye A, Sagna M, Gassama-Dia YK (2008). Plants regeneration from African cowpea (Vigna unguiculata L.) variety. Afr. J. Biotechnol. 16:2828-2833.

Fang J, Chao CT, Roberts PA, Ehlers JD (2007). Genetic diversity of cowpea [ Vigna unguiculata (L.) Walp.] in four West African and USA breeding programs as determined by AFLP analysis. Genet Resour Crop Evol. 54:1197-1209.

FAOSTAT (2006) FAO agriculture database. FAO, Rome. Available at 
http://faostat.fao.org/faostat

Filippone E (1990). Genetic transformation of pea and cowpea by cocultivation of tissues with Agrobacterium tumefaciens carrying binary vectors. Cowpea genetic resources, contributions in cowpea exploration, evaluation and research from Italy and IITA 175-181.

Gamborg OL, Miller RA, Ojima K (1968). Nutrient requirements of suspension cultures of soybean root cells. Exp. Cell Res. 50:151-158.

Garcia JA, Hille J, Goldbach R (1986). Transformation of cowpea (Vigna unguiculata) cells with an antibiotic-resistance gene using a Tiplasmid-derived vector. Plant Sci. 44:37-46.

Garcia JA, Hille J, Vos P, Goldbach R (1987). Transformation of cowpea (Vigna unguiculata) with a full-length DNA copy of cowpea mosaic virus M-RNA. Plant Sci. 48:89-98.

Ikea J, Ingelbrecht I, Uwaifo A, Thotttappilly G (2003). Stable gene transformation in cowpea (Vigna unguiculata L. Walp.) using particle gun method. Afr. J. Biotechnol. 2:211-218.

Ivo NL, Nascimento CP, Vieira LS, Campos FAP, Aragao FJL (2008).Biolistic-mediated genetic transformation of cowpea (Vigna unguiculata) and stable Mendelian inheritance of transgenes. Plant Cell Rep. 27:1475-1483

Kartha KK, Pahl K, Leung NL (1981). Plant regeneration from meristems of grain legumes: soybean, cowpea, peanut, chickpea, and bean. Can. J. Bot. 59:1671-1679.

Kononowicz AK, Cheah KT, Narasimhan ML, Murdock LL, Shade RE, Chrispeels MJ, Filippone E, Monti LM, Bressan RA, Hasegawa PM (1997). Development of transformation system for cowpea (Vigna unguiculata L. Walp ). Adv. Cowpea Res. 361-371.

Latunde-Dada AO (1990). Genetic manipulation of the cowpea (Vigna unguiculata [L.] Walp.) for enhanced resistance to fungal pathogens and insect pests. Advances in Agronomy 44:133-154.

Le BV, Carvalho MH, Zuily-Fodil Y, Thi AT, Van KTH (2002). Direct whole plant regeneration of cowpea [(Vigna unguiculata (L.) Walp.] from cotyledonary node thin cell layer explants. J. Plant Physiol.159:1255-1258.

Li XB, Xu ZH, Wei ZM, Bai YY (1993). Somatic embryogenesis and plant regeneration from protoplasts of cowpea (vigna sinensis). Acta. Botnica. Sinica. 35:632-636.

Li XM (2011). Establishment of in vitro high efficient regeneration system of cowpea (Vigna unguiculata L.Walp.) and screening test for Its resistance to kanamycin. Sichuan Agricultural University, China.

Manoharan M, Khan S, James OG (2008). Improved plant regeneration in cowpea through shoot meristem. J. App. Hortic. 10(1):40-43.

Mao JQ, Zaidi MA, Arnason JT, Altosaar I (2006). In vitro regeneration of Vigna unguiculata (L.) Walp. cv. Blackeye cowpea via shoot organogenesis. Plant Cell Tiss. Org. 87:121-125.

Murashige T, Skoog F (1962). A revised medium for rapid growth and bioassays with tobacco tissue cultures. Physiol. Plantarum 15:473497.

Muthukumar B, Mariamma M, Gnanam A (1995). Regeneration of plants from primary leaves of cowpea. Plant Cell Tiss. Org. 42:153-155.

Muthukumar B, Mariamma M, Veluthambi K, Gnanam A (1996). Genetic transformation of cotyledon explants of cowpea (Vigna unguiculata $L$. Walp) using Agrobacterium tumefaciens. Plant Cell Rep. 15:980-985.
Odutayo OI, Akinrimisi FB, Ogunbosoye I, Oso RT (2005). Multiple shoot induction from embryo derived callus cultures of cowpea (Vigna unguiculata L.Walp.). Afr. J. Biotechnol. 4(11):1214-1216.

Penza R, Lurquin PF, Filippone E (1991). Gene transfer by cocultivation of mature embryos with Agrobacterium tumefaciens-application to cowpea (Vigna unguiculata Walp). J. Plant Physiol. 138:39-43.

Penza R, Akella V, Lurquin PF (1992). Transient expression and histological localization of a gus chimeric gene after direct transfer to mature cowpea embryos. Biotechniques 13:576-580.

Pellegrineschi A (1997). In vitro plant regeneration via organogenesis of cowpea (Vigna unguiculata L.). Plant Cell Rep. 17:89-95.

Perkins EJ, Stiff CM, Lurquin PF (1987). Use of Alcaligenes eutropus as a source of genes for 2,4-D resistance in plants. Weed Sci. 35:12-18.

Popelka JC, Gollasch S, Moore A, Molvig L, Higgins TJV (2006). Genetic transformation of cowpea (Vigna unguiculata L.) and stable transmission of the transgenes to progeny. Plant Cell Rep. 25:304312.

Raji AAJ, Oriero E, Odeseye B, Odunlami T, Ingelbrecht IL (2008). Plant regeneration and Agrobacterium-mediated transformation of African cowpea [Vigna unguiculata (L.) Walp] genotypes using embryonic axis explants. J. Food Agric.Environ. 6:350-356.

Ramakrishnan K, Sivakumar PR, Manickam A (2005). In vitro somatic embryogenesis from cell suspension cultures of cowpea (Vigna unguiculata L.Walp). Plant Cell Rep. 24:449-461.

Raveendar S, Premkumar A, Sasikumar S, Ignacimuthu S, Agastian P (2009). Development of a rapid, highly efficient system of organogenesis in cowpea Vigna unguiculata (L.). Walp. S. Afr. J. Bot. 75:17-21.

Singh BB, Chambliss OL, Sharma B (1997). Recent advances in cowpea breeding. Advances in Cowpea Research. pp 30-50.

Solleti SK, Bakshi S, Sahoo L (2008a). Additional virulence genes in conjunction with efficient selection scheme and compatible culture regime enhance recovery of stable transgenic plants in cowpea via Agrobacterium tumefaciens-mediated transformation. J. Biotechnol 135:97-104.

Solleti SK, Bakshi S, Purkayastha J, Panda SK, Sahoo L (2008b). Transgenic cowpea (Vigna unguiculata) seeds expressing a bean $\alpha-$ amylase inhibitor 1 confer resistance to storage pests, bruchid beetles. Plant Cell Rep. 27:1841-1850.

Stasolla C, Yeung EC (2003). Recent advances in conifer somatic embryo genesis: improving somatic embryo quality. Plant Cell Tiss. Org. 74:15-35.

Yusuf M, Raji AA, Ingelbrecht I, Katung MD (2008). Regeneration efficiency of cowpea [Vigna unguiculata (L.) Walp.] via embryonic axes explants. Afr. J. Plant Sci. 2(8):105-108.

Zaidi MA, Mohammadi M, Postel S, Masson L, Altosaar I (2005). The Bt gene cry2Aa2 driven by a tissue specific ST-LS1 promoter from potato effectively controls Heliothis virescens. Transgenic Res. 14:289-298. 